\title{
REFERENTES EUROPEOS DO DISCURSO LITERARIO DE ROSALÍA DE CASTRO
}

Javier Gómez-Montero

Christian-Albrechts-Universität zu Kiel

doi:10.17075/rcsxxi.2014.028

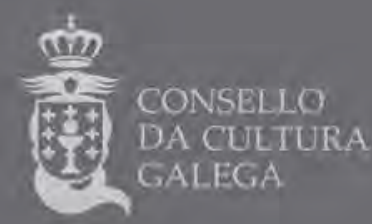



E ben ¿para que escribo?

E ben, porque así semos:

relox que repetimos

eternamente o mesmo.

Esa pregunta, e a súa resposta, pertence á tradición poetolóxica da lírica da modernidade que presenta a desconfianza no potencial comunicativo ou redentor da palabra. No caso específico de Rosalía, as contradicións dunha conciencia marcada intrinsecamente pola disonancia determinan con tal vehemencia a escritura que a representación se converte no escenario do drama da subxectividade, agudizado aínda pola irritante repetición da escritura. A constatación do «sen sentido» garda en si un potencial autodestrutivo que, noutro poema de «Vaguedás», condena a linguaxe ao silencio e a imaxe poética á morte do esquecemento:

\footnotetext{
¡Silencio!

$[\ldots]$

i escribo, escribo ¿para que? ¡Volvede

ó máis fondo da i-alma,

tempestosas imaxes!

¡Ide a morar cas mortas relembranzas!
}

Nos versos finais de «iSilencio!», a voz lírica plasma a impotencia do seu propio discurso, a súa incapacidade de conferir coherencia — aínda que sexa transitoria- á experiencia vital ou poética.

Se a análise literaria se centra na representación da subxectividade, é dicir, se tratamos de describir as figuras estéticas da constitución do suxeito en e mediante a linguaxe desde Cantares gallegos ata En las orillas del Sar, toda a lírica rosaliana resulta ser expresión estética da subxectividade e, neste sentido, a escritura rosaliana forxa unhas figuras estéticas da identidade que se adscriben a unha tradición literaria moderna debedora do pensamento e da estética inaugurados 
co protorromanticismo e ancorada na concepción dun suxeito autónomo, soberano, pero consciente dos límites do cońecemento e da súa representación. É a escisión entre o home e o mundo, entre o eu e a natureza, a orixe, a sociedade e a linguaxe; é aquela Entzweiung que Hegel considerou o momento fundacional da sensibilidade moderna e na que M. Foucault (remitíndose implicitamente a Martin Heidegger) tamén se baseou para definir a figura epistemolóxica do home moderno. Esa figura reflíctese na autofiguración agonal do suxeito e a súa representación en Rosalía.

Tanto o espazo literario e social (tamén o encarnado pola cidade) como o espazo interior da intimidade están presentes no primeiro momento de consolidación dos discursos poéticos no século dezanove e no sistema literario peninsular en que se enmarca a obra de Rosalía de Castro, abonada á crise existencial e tamén enraizada na comunidade (por exemplo, en Cantares gallegos e Follas novas na familia e na nación para á que a voz poética erixe un imaxinario social, subliñando, asemade, a súa subalternidade histórica). Non só en canto á emerxencia de escrituras femininas e polo impulso romántico de conceptualización da nación (e as súas aplicacións específicas na Península Ibérica), senón tamén debido ao tratamento e enfoque das relacións entre individuo e sociedade moderna, a poesía e a prosa de Rosalía de Castro afunden as súas raíces no fondo común das literaturas europeas do século dezanove.

No Anuario de Estudos Literarios Galegos (1997), presentei tres aspectos temáticos, suficientemente tratados xa pola crítica, sintetizados en canto imaxes coas que se constitúe un drama dunha identidade eminentemente agonal — tanto a nivel colectivo coma individual — na lírica de Rosalía: 1. a concepción mítica da orixe, a súa proxección na idea da patria e a súa privatización mediante a afectividade; 2. o ben perdido e $o$ ben soñado como conciencia e nostalxia dunha orixe individual para sempre esvaecida; e 3. as sombras, a negra sombra, como figura da alteridade. As tres imaxes acoutan os límites de toda unha mitoloxía persoal que representa o conflito dun suxeito que, en canto consciencia, se constitúe mediante a integración simultánea de forzas contrarias nunha serie de oposicións e tensións contraditorias que quedan sen resolver. De aí resulta a precariedade que caracteriza a voz poética de Rosalía. Agora lembro, por exemplo, que a representación da paisaxe remite á constitución do suxeito nunha orixe que se proxecta na 
idea da patria. Porén, cando a patria perde a súa condición de imaxe arquetípica e a afectividade persoal privatiza a idea de orixe e constrúe o imaxinario colectivo dela —como amosou María López Sández (2010)—, xorde a posibilidade de constitución agonal do suxeito na temporalidade. Entón, a afectividade proxecta ilusoriamente unha orixe persoal na paisaxe familiar mediante a memoria.

Coido que a representación do suxeito, da consciencia persoal é a chave para percibir ben — como pode subliñar o benemérito tradutor ao alemán de En las orillas del Sar, Fritz Vogelgsang - que Rosalía é precursora da poesía moderna (1991: 327). Eu remarcaría aínda: a escritura poética plenamente moderna de Rosalía eríxea nunha das poetas esenciais da Weltliteratur. Vou enumerar só uns poucos trazos: $1^{\circ}$, a desauratización da linguaxe e a desretorización da imaxe poética; $2^{\circ}$, a construción dun imaxinario cultural para toda unha Gemeinschaft (comunidade no sentido de F. Tönnies —Erdozáin, 2009—, pero de carácter nacional) a partir da paisaxe e a historia, o territorio e a lingua, perfilando o propio con carácter identificador e colectivo para eses grupos sociais - tanto no campo e na costa como nas cidades, en ambientes cultos ou carentes de formación-, é dicir, o propio válido para todos os corpos sociais daquela comunidade (incluídos os emigrantes); $3^{\circ}$, dende o punto de vista da filosofía do suxeito, a súa constitución agonal en continua lide consigo mesmo e a sociedade, adquirindo a existencia o perfil dun agon, dunha loita cun contraente interior metaforizado no amplo campo figurativo dos espectros, fantasmas e da sombra, a negra sombra convertida nun dobre inquietante, no Doppelgänger inscrito nos pregos recónditos da conciencia, un dobre subconsciente emerxente unha vez tras outra; e, por último, $4^{\circ}$, a descontinuidade e diseminación da escritura poética como expresión dunha conciencia disonante e por definición desequilibrada. Xa que logo, hoxe vou rematar a tarefa que abordara nos anos 90 engadindo o principio de descontinuidade estruturadora da escrita poética en Follas novas e En las orillas del Sar e acadando unha lectura dun poema emblemático no cal se artella unha proxección de eu lírico feminino na figura da Margarita do Fausto de Goethe e mais na recepción desta personaxe na literatura francesa.

Pero, antes de todo, comezarei por acoutar o horizonte europeo de lecturas de Rosalía (a súa prosa e a súa lírica beben das fontes do Romanticismo europeo e na escritura feminina). 


\section{O ADN LITERARIO DE ROSALÍA: VIDAS E OBRAS PARALELAS NA LITERATURA EUROPEA}

O ADN da nova escritora Rosalía son as súas amplas lecturas da literatura europea contemporánea, que logo se converten en referencias da súa escritura: as lecturas son un espello das inquietudes da adolescente, as obras literarias forman un magma de inventiva da nova escritora.

Estas lecturas da literatura europea contemporánea, dun lado, constitúen o horizonte mental e un mapa intelectual da nova escritora, pero doutro, no seu conxunto, supoñen tamén unha cartografía textual da súa reivindicación dun "sentir e saber outros», en feminino. Xa no ano 1859, con 22 anos, logo da aprendizaxe da lingua francesa e as lecturas literarias en francés, o prólogo a La hija del mar e as citas de escritoras inglesas/americanas e francesas, as «nais adoptivas» de Rosalía de Castro, testemuñan esa específica sensibilidade, que tamén amosan outras referencias aos «monstros» da xuventude romántica, como "Manfred»/Byron, Ossian, «Paul et Virginie», Victor Hugo, Werther — cuxas dúas frases finais se citan en francés á fronte do capítulo XIV de La hija del mar («des ouvriers portèrent le corps. Aucun prêtre ne l'accompagna») atribuídas sen indicación da obra de Goethe no Sturm und Drang_- Espronceda, Zorrilla, etc.

Para min, a referencia máis importante da nova Rosalía é George Sand: nas dúas vemos non só a formación literaria e a integración social burguesa —ou o paso da fidalguía rural á burguesía urbana- xunto coa función parella que as dúas atribúen á literatura na sociedade (nos Prólogos de La hija del mar e de Indiana $1842^{2}$ ), senón que tamén cultivan estratexias prologais de subestimación ou unha ocultación que, paradoxalmente, son definitorias dunha escritura feminina que se entende como reivindicación de xénero; ao mesmo tempo, ambas as dúas artellan $v$ oces e microsistemas sociais en feminino cun gran potencial identificador para as lectoras (Cantares gallegos, La hija del mar, novela cara á cal — para o personaxe de Teresa — xa se falou do papel de Jane Eyre, 1847). Para estas cuestións —e moitas outras — son e serán básicas no futuro as achegas do libro Canon y subversión que publicaron en 2012 Helena González e María do Cebreiro Rábade.

As converxencias de paradigma na escritura con G. Sand, 1805-76, son máis que evidentes, mesmo Rosalía a pon de modelo explícito cando fala do seu amplo 
Préface a Les Confessions de Rousseau, no que se resaltan os escritos educativos e autobiográficos do suízo. Sublińo outros poucos aspectos que vinculan intrinsecamente a obra de ambas as dúas escritoras:

* reivindicacións das personaxes femininas (p. ex. Lélia, cun profundo desgarro interior);

* denuncia social (a(s) muller(es), os obreiros, o campo, etc.);

* celebración do idilio preindustrial e construción da natureza como espazo simbólico persoal ou social artellado pola conciencia (lémbrolles como na novela La mare au diable [1846] aparece o espazo idílico campestre de Le Berry, cos seus costumes e tradicións labregas, pintorescas, e tamén Les Maîtres Sonneurs [1853] é un modelo dos romans champêtres, régionalistes contemporáneos en Francia). Xusto no Prefacio e capítulo I de La mare au diable, G. Sand deixa fixado o carácter simbólico do discurso literario pola súa incidencia na afectividade humana e nas estruturas emocionais da persoa fronte ás prácticas de análises da sociedade aplicadas por Balzac e logo por Zola.

Outras mulleres notables ás que nomea Rosalía son: J. Roman (adscrita ao proletario- feminismo saintsimoniano), Mme. Delphine Girardin (dramaturga, mulleres protagonistas, esposas), Madame Rolland (revolucionaria), Rosa Bonheur (pintora, protosocialista), Mme. Felicité de Genlis (De l'influence des femmes sur la littérature française, 1811).

Pero eu vou propor as figuras — non sei se moi coñecidas nesta Fisterra- de dúas escritoras alemás ás que, sen dúbida, Rosalía non lera, pero que teñen unha voz, ás veces, tan semellante que podo arriscar e propor a continuidade da escritura literaria entre as tres. Primeiro, Annette von Droste-Hülshoff (1797-1848, unha escritora do canon alemán no cume do Romanticismo nos anos 1830-40). Conta — como para Rosalía — o avoengo familiar dela (nobreza de Westfalia), a formación humanista e os cenáculos cultos que frecuentou, e que se integrou nos mellores ambientes literarios (ela traballou co escritor Levin Schücking, autor de Das malerische und romantische Westfalien, 1845). Na historia da literatura, Annette von Droste-Hülshoff ocupa o panteón romántico xunto con H. Heine, pero sen a ironía deste.

A poeta escribiu moitos poemas sobre a paisaxe de Westfalia, en termos moi emocionalizados e nos que proxecta as inquedanzas máis persoais («Im Grase», «Das Haus in der Heide», «Mondaufgang»: son poemas dos anos 1838 e 1845 
vencellados á paisaxe), e na súa Naturlyrik tamén lle deu á natureza unha relevante función simbólica: o idilio nos poemas dela fai fronte á ameaza da progresiva industrialización no que hoxe ía ser o veciño Ruhrgebiet.

Velaquí un exemplo da súa poesía:

Das Haus in der Heide

Wie lauscht, vom Abendschein umzuckt,

Die strohgedeckte Hütte,

- Recht wie im Nest der Vogel duckt, -

Aus dunkler Föhren Mitte.

Am Fensterloche streckt das Haupt

Die weißgestirnte Sterke,

Bläst in den Abendduft und schnaubt

Und stößt an's Holzgewerke.

Seitab ein Gärtchen, dornumhegt,

Mit reinlichem Gelände,

Wo matt ihr Haupt die Glocke trägt,

Aufrecht die Sonnenwende.

Und drinnen kniet ein stilles Kind,

Das scheint den Grund zu jäten,

Nun pflückt sie eine Lilie lind

Und wandelt längs den Beeten.

Am Horizonte Hirten, die

Im Heidekraut sich strecken,

Und mit des Aves Melodie

Träumende Lüfte wecken. 
Und von der Tenne ab und an

Schallt es wie Hammerschläge,

Der Hobel rauscht, es fällt der Span,

Und langsam knarrt die Säge.

Da hebt der Abendstern gemach

Sich aus den Föhrenzweigen,

Und grade ob der Hütte Dach

Scheint er sich mild zu neigen.

Es ist ein Bild, wie still und heiß

Es alte Meister hegten,

Kunstvolle Mönche, und mit Fleiß

Es auf den Goldgrund legten.

Der Zimmermann - die Hirten gleich

Mit ihrem frommen Liede -

Die Jungfrau mit dem Lilienzweig -

Und rings der Gottesfriede.

Des Sternes wunderlich Geleucht

Aus zarten Wolkenfloren -

Ist etwa hier im Stall vielleicht

Christkindlein heut geboren?

(Droste-Hülshoff, 1994: 64-66)

Logo Annette von Droste-Hülshoff inclúe elementos fantásticos e dramáticos («Der Jüngling im Moore», «Das öde Haus»), tamén motivos da Schauerromantik (ou Romanticismo tétrico) na novela Die Judenbuche (que conta a morte dun xudeu en Westfalen no ano 1842), sen esquecer a introspección, p. ex. no poema «Das Spiegelbild». Conta o paralelo no discurso emocional malia que A. Droste-Hülshoff non chegue a reivindicar a terra como sinécdoque da nación a partir dunha conciencia de subalternidade económica e social —como atopamos en Cantares gallegos - e tampouco a emocionalización da paisaxe ten esa mesma 
dimensión discursiva, definitoria en Rosalía. As dúas superan a tentación costumista polas pegadas simbólicas e subxectivas; alén diso, en Rosalía de Castro tamén temos ambientación nunha natureza ameazadora e primitiva (La hija del mar: en Muxía, Fisterra, O Rostro, na que a terra se fai simbólica expresión do baleiro das figuras femininas e na que o mar é unha figuración presimbólica en canto que matriz da vida, vid. M. García Candeira: 2012).

Pode que a segunda escritora alemá da que vou falar sexa para nós aínda máis pertinente xa que con ela acadamos as liñas de continuidade discursiva que constitúen un paradigma do desgarro en feminino máis radical, na íntima escisión ata chegar á angustia, a pensar na loucura e na morte. É a escritura de introspección e de desexo, de autoanálise ou radical autoobservación (tamén presente, ás veces, en G. Sand, p. ex. en Lélia), que en Rosalía de Castro se vincula co personaxe goethiano excluíndo na autorreferencia o compońente libidinoso (motivo presente no poema «Margarita»).

Para min o referente alemán desta escritura é Karoline von Günderrode (17801806), autora de Gedichte und Phantasien, 1804, Dramen, que formou parte do círculo de Bettina von Arnim, quen adicara a Karoline a novela epistolar Die Günderrode (1840), de Gunda Brentano e dos escritores Savigny e mais Creutzer). Formou parte do protorromanticismo alemán no horizonte de Ossian, Herder, Achim von Arnim e que se suicidou despois dunha tráxica relación. Christa Wolf dedicoulle un estudo en que a considera alma xemelga de Heinrich von Kleist.

As seguintes citas das cartas dela á súa amiga Gunda Brentano dan conta do drama da súa interioridade:

So schwankend sind meine Selbstbeobachtungen. Überhaupt ist mirs ganz unbegreiflich daß wir kein anders Bewustsein haben, als Wahrnehmung von Wirkungen, nirgends von Ursachen. Alles andere Wissen scheint mir (sobald ich dies bedenke) nicht wissenswürdig, solang ich des Wissens Ursache, mein Wissensvermögen, nicht kenne. Diese Unwissenheit ist mir der unerträglichste Mangel, der größte Widerspruch. (1981: 137-8). (Así de vacilantes son as miñas introspeccións. En realidade, resúltame inconcibible que só teñamos conciencia para percibir as consecuencias, pero non para percibir as causas. En canto siga a considerar isto, ningún outro tipo de saber non me resulta digno de cońecer mentres que eu descońeza a causa deste saber, a miña propia capacidade de saber. 
Esta ignorancia supón para min a carencia máis insoportable, a maior contradición). (Tradución de Paz Huete Iglesias)

Nur das Wilde Grose, Glänzende gefälltmir. Es istein unseliges aber unverbesserliches Misverhältniss in meiner Seele; und es wird und mußso bleiben, denn ich bin ein Weib, und habe Begierden wie ein Mann, ohne Männerkraft. Darum bin ich so wechselnd, und so uneins mit mir. (1981:140) (Só me gusta a grandeza salvaxe, brillante. É un desequilibrio desgraciado pero incorrixible desta mińa alma. Pero o desequilibrio vai permanecer e ten que permanecer así porque son unha muller e teño ansias como as ten un home, pero sen a forza dun home. Por iso son tan cambiante e non consigo estar de acordo comigo mesma).

(Tradución de Paz Huete Iglesias)

Para min, o que máis conta son as converxencias discursivas entre Karoline von Günderrode e Rosalía de Castro (o paradigma do desgarro feminino e o agon na autoconstitución subxectiva definidos polo feito de que neles van prevalecer unha autoollada tráxica e as tensións do desexo), a achega dende a subalternidade (social e de xénero) á conciencia da autoría feminina, a reflexión e introspección como marcas estruturais da escrita poética, a constitución do eu como palabra, desexo e desexo de palabra, a construción de espazos dialóxicos da conciencia e —dende o punto de vista da figuración — o trazo de isotopías simbólicas baseadas sexa nunha paisaxe local ou sexa na dimensión cósmica do infinito. Estas mesmas marcas amósanse en poemas como «Ist alles stumm und leer» (do que presento un anaco), «Vorzeit, und neue Zeit» ou «Einer nur und Einer dienen»:

\section{Ist alles stumm und leer,}

Nichts macht mir Freude mehr,

Düfte sie düften nicht,

Lüfte sie lüften nicht;

Mein Herz so schwer!

Ist Alles öd und hin,

Bange mein Herz und Sinn,

Wollte, nicht weiß ich was

Jagt mich ohn Unterlaß, 
Wüßt ich wohin? -

[...]

(Günderrode, 1990: 454)

\section{Vorzeit, und neue Zeit.}

Ein schmaler rauher Pfad schien sonst die Erde.

Und auf den Bergen glänzt der Himmel über ihr,

Ein Abgrund ihr zur Seite war die Hölle,

Und Pfade führten in den Himmel, u[nd] zur Hölle.

Doch alles ist ganz anders nun geworden,

Der Himmel ist gestürzt, der Abgrund ausgefüllt,

Und mit Vernunft bede[c]kt, und sehr bequem zum gehen

Des Glaubens Höhen sind nun demolieret.

Und auf der flachen Erde schreitet der Verstand,

Und misset alles aus, nach Klafter und nach Schu[h]en.

(Günderrode, 1990: 375)

\section{[Einer nur und einer dienen ...]}

Einer nur $\mathrm{u}[\mathrm{nd}]$ einer dienen

Das ermüdet meine Seele.

Rosen nur $\mathrm{u}[\mathrm{nd}] \mathrm{im}[\mathrm{m}]$ er Rosen

Andre Blumen blühn noch bunter

Wie die Bienen will ich schwärmen

Mich in Traubenglut berauschen

In der Lilie Weis mich kühlen

Ruhen in der Nacht der Büsche 
In die heitre freie Bläue

In die Unbegränzte Weite

Will ich wandlen will ich wallen

Nichts soll meine Schritte feßlen

Leichte Bande sind mir Ketten

Und die Heimat wird zum Kerker.

Darum fort $\mathrm{u}[$ nd] fort ins Weite

Aus dem engen dumpfen Leben

Reg erfaßt mit regem Sinne

Alles Holde alles Schöne

Keinem ganz sich hingegeben,

Keine Gränze dem empfinden.

Wehe! wer mit engem Sinne

Einem nur sich Einem weihet

Schmachvoll rächt sich an dem Armen

Alles was er streng verschmähet.

Nicht zur Heimat wird die Weite,

Ungestaltet in die Ferne,

Aufgelößt in leeres Sehnen

Wird der Inhalt so des Lebens.

Schön ist was sich gränzt $\mathrm{u}[\mathrm{nd}]$ gnüget,

Treu um Eines sich beweget

An dem Einen sich erneuet

Wie des Pulses rege Schläge

Stets sich um das Herz bewegen,

Stets zum Herzen wiederkehren

Stets am Herzen sich erneuen,

Sich an seiner Gluth entzünden,

Wehe wer von seinem Herzen

Abwärts suchend sich verirret, 
Nicht zur Heimat wird die Weite

Ungestaltet bleibt das Leben

Ohne Mitte alles Streben.

(Günderrode, 1990: 392-393)

Xa que logo, a sensibilidade poética de ambas as dúas autoras é congruente coas vías de constitución da conciencia persoal nos termos dun agon ou loita espellada no drama da escrita poética.

Para rematar o ADN literario de Rosalía, pódese lembrar que —en vez de novela gótica (ao estilo de The Castle of Otranto, The Monk, etc.) — é moito máis pertinente remitirse ao horizonte referencial que constitúen as escritoras Jane Austen, Emily e Charlotte Brontë (novel of manners con mulleres protagonistas, o que en alemán se chama Entwicklungsroman ou Gesellschaftsroman, moitas veces especificados como Liebesroman) e chegar ata as novelas máis populares de Charlotte Smith, Cummings citadas en La hija del mar en castelán, etc. («El primer loco» sería a primeira novela gótica en sentido estrito, como subliñou Fernando Cabo no seu relatorio do 25.4.2013 neste congreso).

\section{OUTROS MOTIVOS E ESTRUTURAS DE RECEPCIÓN CREATIVA}

A escrita poética de Rosalía afunde as súas raíces nos esquemas enunciativos que xerou a lírica dos románticos europeos: dende a composición cíclica a partir de series de poemas autónomos pero interrelacionados entre si (Heine, DrosteHülshoff) ata as fórmulas de dramatización poética derivadas dos poemas líricos dramáticos, os monólogos dramáticos, diálogos dramatizados (Browning/Tennyson, o que estudara Langbaum, 1996) ata chegar logo á descontinuidade como procedemento dun incipiente hermetismo na escritura poética (que xa practicara Nerval, como estudou Stierle, 1991), xunto coa proliferación e variabilidade das voces poéticas, e sen esquecer motivos protorrománticos vinculados ao fantástico (o inquietante, o sinistro, o máis terrible do subconsciente): o Dobre/Doppelgänger como expresión do retour du refoulé, a emerxencia do reprimido, o que vou amosar cunha interpretación da serie de catro poemas "Todas las campanas...» (con reminiscencias do Fausto, cuxa recepción dende Mme. de Staël se centra na 
figura da nova e inocente Margarita, seducida por Fausto con axuda de Mefistófeles e que en Goethe mata o fillo xerado con Fausto; mesmo Worsworth: «The Afflections of Margarethe»). Lembro, como marco do inminente close reading, que no Fausto I temos o tema ou motivo da angustia de Margarethe no cárcere (reclusión carceraria e postergación pública: verso 3587 e ss., ante unha imaxe da Mater dolorosa; 1984: 114-5, ed. Trunz, que é só un monólogo). Logo no drama de Michel Carré: Faust et Margerite (1850), no acto III reclúese na igrexa e aparéceselle Mefistófeles na escena VI: momentos de penitencia, angustia e diálogo ata a ascensión final, base da ópera de Gounod coa súa salvación (1858).

A escrita dunha introspección radical de Rosalía de Castro céntrase na angustia, desgarro e loucura, íntima escisión e o tormento interior (que tamén é o horizonte semántico do poema "Margarita» de En las orillas del Sar). Ademais, poderíase ver a vinculación da autoproxección en Gretchen: Ía ser Margarita unha Doppelgängerin para Rosalía? E en canto que tal un reflexo de $A$ negra sombra?

Deberíase facer unha análise da descontinuidade como estrutura do discurso poético: dende as composicións en catro poemas «Na Catedral» ao «O toque d'alba» (Follas novas) ata "Margarita» e «Santa Escolástica», pasando por «Orillas del Sar» e mais a serie como a segunda do libro que non leva título (pero prepublicada como «Penumbras»). Porén, voume centrar só na serie 21 «Todas las campanas...», da edición de 1884, que ten catro partes:

Bloque 1: Enterro antiwertheriano.

Bloque 2: Os choros da Morte, pero quen é o suxeito da enunciación, pode que Mefistófeles?

Bloque 3: Angustia e inquedanza de Margarita, loita interior e escisión pola conciencia de culpa, e (cínica) consolación por boca de Mefistófeles.

Bloque 4: Desdobramento e diálogo sobre a curiositas: curiosidade como orixe da culpa, reflexións sobre a inutilidade de querer saber (seguindo o exemplo de Fausto, quen entón ía ser un interlocutor?), enmarcado por un comentador externo.

Velaquí o texto:

Todas las campanas con eco pausado

doblaron a muerto:

Las de la basílica, las de las iglesias,

las de los conventos. 
Desde el alba hasta entrada la noche no cesó el funeral clamoreo.

¡Qué pompa! ¡Qué lujo!

¡Qué fausto! ¡Qué entierro!

Pero no hubo ni adioses ni lágrimas ni suspiros en torno del féretro...

¡Grandes voces sí que hubo! y cantáronle, cuando le enterraron, un réquiem soberbio,

Siente unas lástimas,

¡pero qué lástimas!...

Y tan extrañas y hondas ternuras...,

¡pero qué extrañas!

Llora a mares por ellos,

les viste la mortaja

y les hace las honras...

después de que los mata.

De la noche en el vago silencio,

cuando duermen o sueñan las flores,

mientras ella despierta, combate

contra el fuego de ocultas pasiones,

y de su ángel guardián el auxilio

implora invocando piadosa su nombre.

El de ayer, el de hoy, el de siempre,

fiel amigo del mal,

Mefistófeles,

en los hilos oculto, del lino

finísimo y blanco cual copo de espuma,

en donde ella aún más blanca reclina 
la cabeza rubia,

así astuto y sagaz, al oído

de la hermosa en silencio murmura:

«Goza aquél de la vida, y se ríe

y peca sin miedo del hoy y el mañana,

mientras tú con ayunos y rezos

y negros terrores tus horas amargas.»

«Si del hombre la vida en la tumba

¡oh, bella!, se acaba,

¡qué profundo y cruel desengaño,

qué chanza pesada

le juega la suerte,

le espera a tu alma!»

A la sombra te sientas de las desnudas rocas,

y en el rincón te ocultas donde zumba el insecto,

y allí donde las aguas estancadas dormitan

y no hay hermanos seres que interrumpan tus sueños,

¡quién supiera en qué piensas, amor de mis amores,

cuando con leve paso y contenido aliento,

temblando a que percibas mi agitación extrema,

allí donde te escondes, ansiosa te sorprendo!

— ¡Curiosidad maldita!, frío aguijón que hieres

las femeninas almas, los varoniles pechos;

tu fuerza impele al hombre a que busque la hondura

del desencanto amargo y a que remueva el cieno

donde se forman siempre los miasmas infectos.

- ¿Qué has dicho de amargura y cieno y desencanto?

¡Ah! No pronuncies frases, mi bien, que no comprendo;

dime sólo en qué piensas cuando de mí te apartas 
y huyendo de los hombres vas buscando el silencio.

- Pienso en cosas tan tristes a veces y tan negras, y en otras tan extrañas y tan hermosas pienso, que... no lo sabrás nunca, porque lo que se ignora no nos daña si es malo, ni perturba si es bueno. Yo te lo digo, niña, a quien de veras amo; encierra el alma humana tan profundos misterios, que cuando a nuestros ojos un velo los oculta, es temeraria empresa descorrer ese velo; no pienses pues, bien mío, no pienses en qué pienso.

—Pensaré noche y día, pues sin saberlo, muero.

Y cuenta que lo supo, y que la mató entonces

la pena de saberlo.

Teño que subliñar que a orde dos poemas de En las orillas del Sar nas edicións actuais é moi problemática. Para min a editio princeps ten unha significación con valor hermenéutico cara á estrutura do discurso xa que marca liñas de lectura. Ocorre que non podo lembrar agora o debate crítico e a historia das edicións, como xa fixen hai máis de 15 anos, documentado no apéndice I (1997), pero si que vou referir só un resumo das conclusións de entón: temos 30 grupos de poemas ou series e mais 11 poemas illados, algúns con título, outros sen el, e cada cal empeza e remata cunha vińeta, mentres que cada poema das series se separa con asteriscos. Se dinamitamos as series — contando só e unha tras outra as 98 pezas da princeps ou as 109 da segunda edición, na que M. Murguía engadiu 11 poemas, e como se fai dende as edicións de V. García Martí (1944) e A. del Hoyo (1977)—, logo pérdese un principio de estruturación do libro —o da descontinuidade-, que ten unha importante relevancia hermenéutica. Este principio compositivo da descontinuidade ten coherencia propia xa que permite vincular conceptos, motivos poéticos, personaxes, paradigmas emocionais ou de reflexión e recońecer axiña outros principios do discurso poético como a variabilidade figurativa, a pluralidade de perspectivas, e — mesmo nas series — os cambios de 
soporte e posición da voz poética e a súa diseminación. Xa que logo, todas estas estratexias remachan a constitución agonal do suxeito na escritura poética rosaliana. Agora paso á análise da serie XXI.

\section{A DESCONTINUIDADE DA ESCRITURA E VARIABILIDADE DA VOZ POEMÁTICA, ESTRATEXIAS DISCURSIVAS DA POÉTICA DA MODERNIDADE (E DO INCIPIENTE HERMETISMO DA ESCRI- TURA POÉTICA)}

Analizando estes catro poemas como un conxunto e mentres que os vínculos argumentais aparecen moi diluídos, descóbrese a súa sutil interrelación a nivel figurativo e semántico; aínda que, por outra parte, será imposible reconstruír o seu sentido con claridade, pois o argumento é enigmático e só son recoñecibles algunhas pistas xa que queda sen aclarar a identidade dos personaxes e as voces que interveñen, as accións apenas insinúan e vélanse conexións explícitas dos poemas entre si. Non obstante, motivos tétricos ou góticos (Schauermotive: morte, culpa, condena, maldición, dificultade de expiación, etc.) configuran o poema. Así, as lúgubres badaladas e o solemne enterro (1), un personaxe que trae a mortalla (quizais unha alegoría da morte ou do diaño mesmo (2), unha piadosa e nova rapaza loura que no seu leito é consumida por secretas paixóns e dores (3) e que, sen dúbida, remite á Margarita do Fausto de Goethe e ás súas ulteriores adaptacións francesas, pois Mefistófeles incítaa a gozar da vida ante a inevitable morte e, finalmente, unha meditación dialogada sobre a causa de tanta mágoa e decepción humanas cunha alusión á morte da nova muller unha vez coñecida aquela («la mató entonces / la pena de saberlo»). Aquí móstrase o vínculo de unión do ciclo: o tormento da existencia e a dor unha vez entendido o seu desatino, nos que se inscribe o desequilibrio ontolóxico do suxeito lírico. Ao redor do campo semántico da morte humana, a serie narrativa de poemas recrea situacións dramáticas que derivan en reflexións, pensamentos e sensacións enmarcadas, ás veces, por suxestivas imaxes de referente paisaxístico.

A linguaxe poética vai fluíndo de acordo con ritmos alternantes. Combínanse poemas estróficos dispares e de diferentes versos. Ás veces, insinúanse simetrías que enseguida poden esvaecerse, emerxen rimas asonantes nos versos pares res- 
pectivamente. A análise métrica pon de manifesto a preferencia de formas abertas e irregulares, aínda que acordes e cadencias flúen ritmicamente, interrómpense e son retomados. A cesura máis pronunciada márcaa a irrupción de estrofa de peche.

O rechamante é que este acompasado fluír dos versos ata o clímax final e as constantes semánticas e figurativas apuntadas contrastan coa fragmentación argumental e coa incerta identidade de personaxes e voces, todo isto intensificado pola sucesión alternante de momentos narrativos, dialogados, descritivos ou reflexivos. A isto súmase a variable posición da voz lírica segundo as escenas e a alternancia dos suxeitos de enunciación, a ocultación da identidade dos actores e interlocutores (salvo Mefistófeles). E aínda que queda suxerida a súa continuidade, non cabe en absoluto adxudicar con exactitude os pronomes e persoas gramaticais nin as súas correspondencias exactas.

Cal é a identidade do morto? Un notable, tendo así o poema un aspecto de crítica social como propoñen M. Mayoral (na súa edición, p. 126) e C. Davis (1987: 392)? Quen se lamenta dos mortos sendo, ao mesmo tempo, a causa da súa tráxica fin? Eu vexo máis ben a inversión do emocionante enterro do mozo Werther na intimidade da familia da súa amada Lotte. Quizais unha figura alegórica, chamémola Morte, Mágoa ou Curiosidade (con maiúsculas respectivamente). Mais, non podería ser o Diaño mesmo, personificado logo en Mefistófeles?

Están relacionadas a "fermosa» do terceiro poema e a «nena» ou «amor dos meus amores» interpelada no cuarto? Existe unha relación entre esta, a "ansiosa» da primeira estrofa, «en axitación»e a persoa que morre a resultas da mágoa do coñecemento aquí mesmo?

Parece evidente, pero resulta imposible reconstruír a ciencia certa a constelación interpersoal nin a da comunicación neste último poema. Pero, sen dúbida, podería ser Mefistófeles o suxeito gramatical do segundo poema e, entón, na súa primeira estrofa teriamos as bágoas de Margarita a fermosa moza do terceiro poema («niña» no cuarto). É ela quen interpela á «curiosidade maldita» que a levou á culpa unha vez «chafado o veo» («Margarita», II, verso 36). E, aínda así, quen é o suxeito da enunciación do primeiro poema que parece ser a mesma voz de quen fai o comentario final?

Todas as opcións serían factibles, pero non hai certeza ningunha. A pista con máis probabilidade é a pegada do Fausto e a conexión Margarita-Mefistófeles, 
fundamentada tamén tematicamente no motivo da culpa, o da súa proscrición pública e o da morte, pero non unha morte por coita amorosa como induce a íntima e mutua interpelación a dous amantes («amor de mis amores», «mi bien»).

Serían, antes ben, Fausto e Margarita os que parlamentan? Ben ao contrario, o motivo da morte da rapaza son a «hondura del desencanto amargo», ou mellor, os seus cońecementos ao respecto e o desengano que isto supón (III, 21), e a percepción dos abismos máis profundos da conciencia (IV, 23).

A intimidade que presupoñen faise como «a quen de verdade amo» e «cando de min te apartas» apunta non a unha intimidade erótica, senón a dos abismos da angustia máis desoladora da existencia. Aínda habería que aclarar se a conversa apenas iniciada se continúa e se a rapaza/Margarita responde á interpelación (IV, 18-26). Así parece e habería eventualmente que explicitalo coa inclusión dun guión no verso 22 («Yo te lo digo, niña...»), onde reiniciaría o seu discurso Mefistófeles. Isto é congruente tendo en conta o desenlace do diálogo (verso 27: "-Pensaré noche...»), pero, non obstante, atopamos a mesma persoa gramatical (a primeira persoa, "penso», "pensarei») ao comezo e ao final do período.

Así pois, quedan puntos dabondo por aclarar, tamén no relativo á identidade das voces. Por iso sería máis factible buscar a coherencia do diálogo e o desenvolvemento escénico considerando o texto no seu carácter fragmentario, dándolle a estrutura dun monólogo dramatizado por varias voces (así cadra moi bei que A. López-Casanova chame a atención sobre o feito de que o poema «A la sombra te sientas...» sexa un exemplo dunha escenificación retórica do diálogo dramático ([1985 $\left.\left.{ }^{1}\right], 37\right)$. Son as voces da conciencia que se axustan segundo unha ficción conversacional articulada en escenas máis ou menos inconexas. Dende logo, non ofrece a menor dificultade interpretar a cuarta escena ou poesía nos termos dunha autointerpelación retórica mediante a escisión da conciencia en tres persoas gramaticais (eu, ti, ela). O impreciso desenvolvemento dos diálogos débese á indeterminación dos pronomes persoais e á arbitraria alternancia de voces en primeira, segunda e terceira persoa.

Este procedemento lingüístico de drama-ficción é recorrente na escritura poética de Rosalía e — trátese dunha dramatización tanto monolóxica como dialóxi$\mathrm{ca}$ - indica sempre unha escisión da conciencia en diferentes persoas gramaticais. Dese modo, os pronomes gramaticais vense desprovistos de toda función referencial para converterse en mero soporte lingüístico da reflexión ou enunciado, que 
non se dirixe necesariamente a interlocutor ningún, senón ao suxeito mesmo da enunciación.

A miña interpretación pon de manifesto a alta eficacia poética da descontinuidade como principio compositivo na escritura poética de Rosalía. Tal descontinuidade non concirne exclusivamente aos argumentos (estados de conciencia, sentimentos, pensamentos, etc.), como nesta serie de poemas, nin á súa fragmentación enigmática, hermética. A descontinuidade afecta non menos ao suxeito da enunciación, á voz lírica. (E lémbrese que xa M. Mayoral na «Introducción» á súa edición, pp. 62-64, e F. Rodríguez (1988: 263-264) indicaron procedementos da fragmentación argumental en certos poemas de Follas novas).

En Rosalía, comprobamos tamén que a erosión da ensamblaxe argumental (segundo un suposto desenvolvemento previsible ou lóxico) se corresponde coa combinación de confidencias líricas con representación escénica e pasaxes narrativas e, mesmo, cunha despersonalización da voz poética. Os procedementos descritos de textualización descontinua non poñen en absoluto en entredito a coherencia semántica do poema, senón que potencian a expresión da fraxilidade da conciencia e, con iso, cimentan na escritura poética aquela construción agonal do suxeito tan especificamente rosaliana. É dicir, esa descontinuidade da escritura expresa estados de conciencia estruturados pola disonancia, pola coexistencia de forzas e momentos discordantes e por fundamentarse ese suxeito na incerteza, na perda de toda base de seguranza que puidese harmonizar os principios contrarios e en litixio en que se debate a conciencia persoal. A desolación - como remarca X. Alonso Montero- e a desesperación cébanse no coñecemento de que a existencia humana haberá de estar transida pola dor: "Penso en cousas...».

O texto achega tamén un momento de reflexión: é o coñecemento a causa da tristeza e non a tristeza en si («la pena de saberlo ») e, así mesmo, no horizonte semántico do poema emerxe implicitamente a figura da negra sombra, o que me permite seguir unha pegada de lectura para suxerir unha lińa de continuidade entre ambas as dúas composicións, como xa expliquei na miña tese de habilitación (1996: 310-315, publícanse aquí as páxinas pertinentes no apéndice 2).

Non sei se houbo discusión do aspecto da súa inclusión na serie «O toque de alba», que a pecharía, como dispón Varela Jácome na súa edición de 1982 (de acordo con R. Carballo Calero - quen insistiu no tema unitario da «memoria do pasado»- e segundo a princeps, pp. 50-52 e mesmo a edición de 1909, pp. 
83-85). O certo para min é que o poema da negra sombra é o clímax da serie de catro poemas artellados polo principio da descontinuidade e, así mesmo, polo da interconexión motívica, figurativa e semántica. Non vou subliñar máis que, primeiro, a continuidade dunha voz poemática en diálogo alternante sexa coa campá (1), coa natureza («mar», «ceo», 2), cos pensamentos (3) e, logo, a crecente abstracción do motivo central: dende os «despertares» (v. 9) «mitá sombras» (v. 15 na primeira parte) ata o "fantasma que me aterra» (na segunda, v. 3 ou 51) e a última explosión da negra sombra como figuración inscrita na mesma isotopía do «negro olvido» (no poema terceiro, v. 7 ou 67) e mais a da nota «aterradora»e «pavorosa» (vv. 17, 27), a «amenaza» da persecución (no segundo anaco, v. $11 \mathrm{ou}$ 59). De feito, a circularidade da serie é perfecta grazas á liña de conexión entre os «despertares» (vv. 9 e 33) e "os cabezales» (IV, 3 ou v. 71) e mais a ligazón entre a alba ou aurora do primeiro poema (v. 5, 23, 45 e v. 29, 39, 49) e a aurora do último (IV, 12 ou 80), aquí en contraste explícito coa noite.

Xa que logo, o agon é a figura estruturadora da semántica do poema: loita dos recordos contra a nada do esquecemento, antagonismo da luz e as sombras, lide do pracer contra o terror, antítese entre onte, hoxe e a eternidade..., o agon define o percorrido da lectura. Alén do carácter subxectivo dos referentes e da experiencia íntima, o máis rechamante na mitoloxía persoal que abrangue todo «O toque de alba» é o elemento sinistro, das Unheimliche que dicía S. Freud, case o fantástico da sombra, volta un dobre, un Doppelgänger que emerxe do subconsciente reprimido como un retour du refoulé... De feito, a negra sombra pode verse tamén como o resultado dun desdobramento da conciencia, a emerxencia do outro no mesmo, a figura máis emblemática da constitución agonal do suxeito na poesía de Rosalía de Castro, a xenial concreción daquel «fantasma do ben perdido» que na serie «Na catedral» tamén é expresión do conflito e das disonancias na autopercepción dunha diferenza desequilibrante do ser —o eu que, asemade, é outro, mais radicalmente o mesmo:

Cando penso que te fuches, negra sombra que m'asombras, ó pé dos meus cabezales tornas facéndome mofa.

Cando maxino qu'es ida, 
no mesmo sol te m'amostras,

i eres a estrela que brila,

i eres o vento que zoa.

Si cantan, es ti que cantas;

si choran, es ti que choras;

i es o marmurio do río,

i es a noite, i es a aurora.

En todo estás e ti es todo

pra min i en min mesma moras,

nin m’ abandonarás nunca,

sombra que sempre m'asombras.

(«O toque d'alba», vv. 69-84)

Así pois, para concluír, en En las orillas del Sar a alteridade do suxeito exprésase non só baixo a forma de confidencias íntimas, senón que implica a toma de conciencia e un acto de reflexión: aquí, por un lado, o discurso poético consegue obxectivar a conciencia grazas aos procedementos de dramatización, pero, polo outro lado, as múltiples capas da escritura poñen de manifesto tanto a alteridade como a vontade, o desexo de estabilización desa identidade subxectiva na escritura poética. E, finalmente, o abandono e a superación de formas pechadas ou coherentes de composición corren paralelos á fragmentación da experiencia e dos procesos de conciencia. Cando se rompe esa lińa de continuidade entre os catro textos da serie XXI (e tamén en "O toque de alba»), apenas se perciben estes aspectos e a súa transcendencia discursiva e, así mesmo, poética, que son características da poesía moderna, como xa puxeron de manifesto K. H. Stierte a propósito de Nerval (1967) e H. Friedrich a partir do simbolismo francés (1957). E o lector vai agradecer en ambas as dúas composicións a eficacia poética da descontinuidade xa que esta remacha o potencial de suxestión da linguaxe mesmo se as figuracións fosen herméticas ou polisémicas como son as fantasmas e as sombras rosalianas. 


\section{REFERENCIAS BIBLIOGRÁFICAS}

\section{A. Textos}

Carré, Michel (1850): Faust et Margerite, Paris (Google Books).

Castro, R. de (1880): Follas novas. Versos en gallego. Precedidos de un prólogo de Emilio Castelar, Habana, La Propaganda Literaria / Madrid, La Ilustración Gallega y Asturiana.

Castro, R. de (1884): En las orillas del Sar. Poesias de Rosalia Castro de Murguía, Madrid, Establecimiento tipográfico de Ricardo Fe.

Castro, R. de (1909a): Obras completas de Rosalía de Castro. I. En las orillas del Sar. [Prólogo de Manuel Murguía]. Madrid, Librería de los sucesores de Hernando.

Castro, R. de (1909b): Obras completas de Rosalía de Castro. III. Follas novas, Madrid, Librería de los sucesores de Hernando.

Castro, R. de (1978): En las orillas del Sar. [Edición, introducción y notas de M. Mayoral]. Madrid, Castalia.

Castro, R. de (1982): Poesía completa en galego. [Edición de B. Varela Jácome]. Vigo, Xerais.

Castro, R. de (1985): En las orillas del Sar. [Edición facsímil, 1884]. Madrid, Confederación Española de Gremios y Asociaciones de Libreros.

Castro, R. de (1985 e 1995²): Antología poética. [Introducción, edición y notas de A. López-Casanova]. Madrid, Alhambra Longman.

Castro, R. de (1990²): En las orillas del Sar. [Edición de X. Alonso Montero]. Madrid, Cátedra.

Castro, R. de (1990): Follas novas. [Edición de M. Mayoral e B. Roig]. Vigo, Xerais.

Castro, R. de (1993): Follas novas. [Edición de H. Monteagudo e D. Vilavedra]. Vigo, Galaxia.

Castro, R. de (1995): Cantares gallegos. [Edición de M. X. Lama López]. Vigo, Galaxia.

Castro, R. de (1991): An den Ufern des Sar. [Übersetzt von Fritz Vogelgsang]. Frankfurt, Suhrkamp.

Droste-HüLshoff, Annette von (1994): Sämtliche Werke in zwei Bänden, herausgegeben von Bodo Plachta und Winfried Woesler. Band I: Gedichte, Frankfurt a.M., Deutscher Klassiker Verlag.

Goethe, J. W. v (1984): Faust, herausgegeben und kommentiert von Erich Trunz. München, Beck.

Günderrode, Karoline von (1981): Der Schatten eines Traumes. Gedichte, Prosa, Briefe, Zeugnisse von Zeitgenossen. [Edición de Christa Wolf]. Darmstadt, Luchterhand.

Günderrode, Karoline von (1990): Sämtliche Werke und ausgewählte Studien. [Edición de Walter Morgenthaler]. Bd. I: Texte, herausgegeben von Walter Morgenthaler unter Mitarb. von Karin Obermeier und Marianne Graf. Basel, Frankfurt a.M., Stroemfeld / Roter Stern. [Historisch-Kritische Ausgabe].

SAND, G. (1980): Indiana, París, Gallimard.

\section{B. Estudos CRÍticos}

ACTAS do Congreso internacional de estudios sobre Rosalía de Castro e o seu tempo, Santiago de Compostela, Consello da Cultura Galega / Universidade de Santiago de Compostela.

Alonso Montero, X. (1985): En torno a Rosalía, Madrid, Júcar.

Bouza Brey, F. (1953): "El tema rosaliano de negra sombra en la poesía compostelana del siglo XIX», Cuadernos de Estudios Gallegos, VIII:25, 227-278.

Corona Marzol, G. (1982): «Una lectura de Rosalía», Revista de Literatura, XLIV, 25-62.

Carballo Calero, R. (19813): Historia da literatura galega contemporánea. 1808-1936, Vigo, Galaxia. 
Costa Calvell, X. (1986): «Posible significado existencial e metafísico da "negra sombra" rosaliana», en Actas do Congreso internacional de estudios sobre Rosalía de Castro e o seu tempo, Santiago de Compostela, Consello da Cultura Galega / Universidade de Santiago de Compostela, II, 239-241.

Courteau, J. (1986): «A reconstrução da sombra na poesía de Rosalía de Castro», en Actas do Congreso internacional de estudios sobre Rosalía de Castro e o seu tempo, Santiago de Compostela, Consello da Cultura Galega / Universidade de Santiago de Compostela, II, 243-250.

Courteau, J. (1995): The Poetics of Rosalia de Castro's negra sombra, Lewiston / Queenston / Lampeter, The Edwin Mellen Press.

Davies, C. (1987): Rosalía de Castro no seu tempo, Vigo, Galaxia.

ErdozÁrn, Ana Isabel (2009): «Ambivalencias de la gran ciudad en F. Tönnies y G. Simmel: Comunidad e indivdualiudad", en Urbes Europaeae. Modelos e imaginarios urbanos para el siglo XXI. Paradigmes et imaginaires de la ville pour le XXIe siècle. Herausgegeben von [Javier Gómez-Montero und Christina Johanna Bischoff]. Kiel, Verlag Ludwig, 106-126.

Friedrich, H. (1957): Die Struktur der modernen Lyrik, Reinbeck bei Hamburg, Rowohlt.

García Calvo, A. (1975): «Acerca de la sombra de Rosalía», Los Cuadernos de la Gaya Ciencia, I, Madrid, $25-48$.

GómeZ-Montero, J. (1986): «El paisaje, el viajero, el camino blanco y otros motivos poéticos recurrentes en Rosalía de Castro y en Antonio Machado", en Actas do Congreso internacional de estudios sobre Rosalía de Castro e o seu tempo, Santiago de Compostela, Consello da Cultura Galega / Universidade de Santiago de Compostela, II, 113-125.

GómeZ-Montero, J. (1996: tiposcripto inédito): «Die Unzulänglichkeit der poetischen Rede. Studien zur frühen Lyrik der Moderne in Spanien (J. de Espronceda - G. A. Bécquer - R. de Castro - R. M. del ValleInclán - A. Machado» (Tese de habilitación de cátedra, Colonia: 19.1.1996).

Gómez-Montero, J. (1997): «O vaso quebrado. Imaxes da identidade na poesía de Rosalía de Castro», Anuario de Estudios Literarios Galegos, 11-46.

González Fernández, Helena / María do Cebreiro Rábade Villar (2012): Canon y subversión, La obra narrativa de Rosalia de Castro, Barcelona, Icaria.

Langbaum, Robert (1996): La poesía de la experiencia, Granada, Comares. (De guante blanco).

López SÁndez, María (2010): Paisaxe e nación, Vigo, Galaxia.

Mayoral, M. (1974): La poesía de Rosalía de Castro, Madrid, Gredos.

Murguía, M. (1886): Los precursores, A Coruña, Latorre y Martínez Editores.

PAто, H. (1986): «Y, entre todas las sombras una», en Actas do Congreso internacional de estudios sobre Rosalía de Castro e o seu tempo, Santiago de Compostela, Consello da Cultura Galega / Universidade de Santiago de Compostela, II, 251-257.

Piñero, R. (1951): «Siñificado metafísico da saudade», en Presencia de Galicia, Grial, 1, Vigo, 7-27.

Piñero, R. (1952): «A saudade en Rosalía», en VV. AA., 7 ensayos sobre Rosalía, Vigo, Galaxia, 95-109.

Piñero, R. (1953): «Para unha filosofía da saudade», en La Saudade, Vigo, Galaxia, 11-39.

Poullain, C. H. (1972): Rosalía de Castro de Murguia et son oeuvre poétique (1837-1885), Lille, Université de Lille .

Poullain, C. H. (1974): Rosalía Castro de Murguía y su obra literaria, Madrid, Editora Nacional.

Rodríguez, F. (1988): Análise sociolóxica da obra de Rosalia de Castro, [A Coruña], AS-PG.

Stierle, K. H. (1967): Dunkelheit und Form in Gérard de Nervals 'Chimères', München, W. Fink. 
STIERLE, K. H. (1991): «Diskontinuität. Der Ursprung einer Kategorie des modernen Dichtens bei Nerval und Goethe», en K. Maurer / W. Wehle (Hg.), Romantik-Aufbruch zur Moderne. Romanistisches Kolloquium, 5. München, W. Fink, 427-457.

VArela, J. L. (1958): Poesia y Restauración cultural de Galicia en el siglo XIX, Madrid, Gredos.

VArela, J. L. (1970): «Rosalía y sus límites», en La transfiguración literaria, Madrid, Editorial Prensa Española, 195-210.

Villanueva, D. (1986): «Nova aportación ás poesías completas de Rosalía e á súa hermenéutica», en Actas do Congreso internacional de estudios sobre Rosalía de Castro e o seu tempo, Santiago de Compostela, Consello da Cultura Galega / Universidade de Santiago de Compostela, I, 113-129.

Vonhoff, Gert (1998): Naturlyrik: über Zyklen und Sequenzen im Werk von Anette von Droste-Hülshoff, Uhland, Lenau und Heine, Frankfurt am Main, Peter Lang. 


\section{APÉNDICE I}

Alle wissenschaftlichen Studien zu En las orillas del Sar gehen von dieser kontinuierlichen Textdisposition aus, die textkritisch nicht problematisiert wurde. Auffällig ist dabei die Abwechslung von Einzelgedichten und mehrteiligen Kompositionen mit Titeln wie «2/1. Orillas del Sar», «14/13. Los tristes», «15/14. Los robles», «29/28. ¡Volved!», «40/39. Las canciones que oyó la nińa», «58/57. Santa Escolástica», «71/70. A la luna» (und ausnahmsweise einteilig «41-40. La canción que oyó en sueños el viejo» und «82/81. Las campanas»). All diese Titel stammen aus der editio princeps; deren Einzelteile sind 1884 und in allen späteren Ausgaben mit römischer Zählung versehen. Weitere mehrteilige Gedichte ohne Titel weisen bereits seit der Erstausgabe ebenfalls römische Ziffern auf (wie 24/23, 28/27, 42/41, 50/49, 51/50, 57/56 und 64/63). Daraus und aus der großen Anzahl von losen Gedichten ergibt sich scheinbar ein Beliebigkeitsprinzip in der Anordnung vieler Gedichte, das in der Sekundärliteratur mit der Unbekümmertheit der Autorin oder mit ihrer Schwächung durch die tödliche Krebserkrankung zur Zeit der Veröffentlichung des Bandes gerechtfertigt wird. Man hat spekuliert, daß M. Murguía die Publikation des Bandes aufmerksamer verfolgte als Rosalía. Sicher muß M. Murguía für manipulierende Eingriffe in der zweiten Ausgabe verantwortlich gemacht werden, wie X. Alonso Montero hervorgehoben hat. Dazu zählen nicht nur stilistische Korrekturen am Text, sondern vor allem die Hinzufügung von elf Gedichten, darunter ein Eröffnungs- und ein Abschlußgedicht, in denen ein Akt christlicher Resignation die im Band dominierende radikale Destabilisierung des Bewußtseins ausgleichen soll.

Werden die erste und die zweite Ausgabe mit allen anderen verglichen, stellt sich eine noch größere Überraschung ein: Die scheinbaren Einzelgedichte waren 1884 keineswegs in so loser Folge aneinandergereiht. Vielmehr sind eine ganze Reihe davon zu festen Gruppierungen zusammengestellt, so daß sich dabei eine in ihrer Tragweite bislang nicht erkannte Gliederung des Bandes ergibt: Einige Einzelgedichte fügen sich zu einheitlichen Serien auf der Grundlage einer strukturellen Diskontinuität. Typographisch sind solche unbetitelten Serien denkbar einfach kenntlich gemacht. Ihr Beginn ist jeweils durch eine Vignette, ein Kapitälchen und ein neues Blatt unübersehbar; die Serien werden wiederum durch eine schlichtere Schmuckzeichnung am Blattende geschlossen. Sollte der 
letzte Vers der Serie auf eine Vorderseite fallen, dann bleibt die Rückseite unbedruckt. Voneinander sind die Einzelgedichte dieser Serien nicht durch römische Ziffern getrennt, sondern durch drei Sternchen $(* * *)$, die wohl in den Obras completas und in den späteren Ausgaben übernommen und darüber hinaus auch nach allen mehr- oder einteiligen Gedichten hinzugefügt wurden. In der princeps jedoch trennten die drei Sternchen nur die Einzelgedichte der unbetitelten Serien. Insgesamt ergeben sich in der princeps 41 Gruppen von Gedichten, die jeweils auf einem neuen Blatt, mit Kapitälchen und Vignette, beginnen; einige sind betitelt, andere nicht; die Einzelgedichte sind bald mit römischen Zahlen, bald mit drei Sternchen voneinander getrennt; und schließlich sind nur elf unbetitelte Gedichte gänzlich isoliert, so daß sie für sich allein stehen.

Aus der Disposition der Gedichte als bisweilen zusammenhängende Serien in der ersten und zweiten Ausgabe von En las orillas del Sar ergeben sich textuelle Verknüpfungs- und Verflechtungsmöglichkeiten bei der Lektüre und Analyse, die in den späteren Ausgaben nur schwer entdeckt werden können bzw. nicht mehr so evident sind. Allein C.H. Poullain hat unter ausschließlich inhaltlichen Gesichtspunkten eine Einheit zwischen einigen Gruppen der scheinbar nur für sich stehenden Gedichte herzustellen versucht; eine semantische Kohärenz konnte er allerdings nicht nachweisen, weil er die typographische Anordnung der princeps nicht berücksichtigte und zum Teil andere Serien bildete. Unter Beachtung der ursprünglichen Serien läßt sich hingegen eine strukturelle Einheit erkennen, deren Kohärenz auf kompositorischer Diskontinuität, semantischer und bisweilen auch motivischer Verknüpfung der Einzelteile, figurativer Variabilität, Perspektivenvielfalt und Standortwechsel des Sprechers basiert. Es wird folglich ersichtlich, daß die semantische Kohärenz sich dank der Verflechtung der Gedichte einstellt und daß die Darstellungsebene für die Erschließung des strukturellen Zusammenhangs dieser Gedichte eine hermeneutische Relevanz aufweist.

Anhand der Serie in der die Gedichte 52/51 bis 55/54 gruppiert sind, soll dieses Phänomen exemplarisch untersucht werden (auf die Erörterung eines weiteren Zyklus, der sogar mit dem Titel «Penumbras» (Gedichte 3/2 bis 11/10) vorab publiziert, verzichte ich heute. Die vorangehenden, etwas umständlichen Ausführungen waren mithin als philologische und textkritische Begründung einer Textanalyse notwendig, die das agonale Prinzip der Subjektkonstitution in der poetischen Rede bei R. de Castro erkennen läßt. 


\section{APÉNDICE II}

Solche paradox positivierten Schatten erfassen im weitesten Sinne eine durch die persönliche Innerlichkeit affizierte Projektion des Selbst. Sie beziehen sich auf etwas anderes, das Bestandteil des eigenen Selbst ist - sie definieren also die Identität mit. Auf dieser Grundlage soll nun die hermeneutische Erschließung der Schatten-Motivik als Figur der Alterität und als Beispiel für die agonale Subjektkonstituierung in der Lyrik Rosalía de Castros unternommen werden. Der Konflikt zwischen Einem und Anderem läßt sich am besten nachvollziehen, wenn die Interpretation des Gedichts «Cando penso que te fuches...» dessen Kontextualisierung in der zweiten Sektion von Follas novas ( $i D o$ íntimo!», wie «Na catedral») berücksichtigt.

R. Carballo Calero hielt das Gedicht für das abschließende Fragment einer thematisch zusammenhängenden Serie aus drei Teilen, in der sich die Motive spiegeln oder ergänzen; dabei vermerkte er auch, daß solche Gruppierungen sich des öfteren im Band finden lassen (hinzu kämen «iMar! cas túas auguas sin fondo...» und «Cava lixeiro, cava...»), und auch G. Corona Marzol stützte sich bei seiner Interpretation des Schatten-Motivs als "presencia de una ausencia» auf diese benachbarten Gedichte. Obgleich M. Mayoral den Seriencharakter dieser drei Texte abstreitet, da die Einzelkompositionen nicht — wie sonst in anderen Fällen - römisch durchnumeriert sind, lohnt es sich, in diese Auseinandersetzung einzugreifen. In der ersten und zweiten Ausgabe von Follas novas (1880 und 1909) sind die drei Gedichte (wie alle anderen) jeweils auf einem einzelnen Blatt abgedruckt (und zwar auf S. 50-52 bzw. 83-85); den Titel ersetzen drei Sternchen $\left(^{* *}\right)$. Nun könnte man diese nicht bloß als Titelersatz, sondern als Trennungszeichen innerhalb einer Serie auffassen und —wie B. Varela Xácome in seiner Ausgabe - diese drei Texte dem letztbetitelten Gedicht ( $\mathrm{O}$ toque de alba», jeweils auf S. 47-49 bzw. 81-82 der frühen Ausgaben) zurechnen, so daß sich hier eine vierteilige Serie ergäbe. B. Varela Xácome erklärt durchgängig die betitelten Gedichte zum ersten Glied einer Gedichtserie und numeriert die Verse fortlaufend (vgl. hierzu S. 230-232). Da der jeweilige Index in den beiden frühen Ausgaben die Gedichte einzeln für sich auflistet und nur die erste Sektion («Vaguedás») — die zwanzig Einzelgedichte des Bandes— mit römischen Ziffern fortlaufend numeriert ist, ist zwar die Legitimität solcher Gruppierungen formell 
nicht ganz abgesichert, dem etwaigen semantischen oder motivischen Zusammenhang mehrerer benachbarter Gedichte tut dies dennoch keinen Abbruch. Die Lektüre des Bandes ist durch die Serienbildung gewiß nicht beeinträchtigt oder verfälscht, vielmehr eröffnen sich damit bisweilen neue analytische Möglichkeiten. Demnach darf vermutet werden, daß der Gedichtanordnung in der ersten Ausgabe eine hermeneutische Relevanz zugesprochen werden kann —ein Verdacht, der sich im Falle von En las Orillas del Sar zur Gewißheit erhärten wird, wie im nächsten Abschnitt erörtert werden soll.

Mit den vorgeschlagenen Prämissen soll diese Frage anhand einer zusammenhängenden Analyse der vier Einzelgedichte geprüft werden (der Einfachheit halber werden die Verse durchlaufend numeriert). In «O toque de alba» wiederholen sich einige strukturelle Aspekte, die bei der Interpretation von «Na catedral» bereits herausgearbeitet wurden. Beispielsweise kehren die zeitliche Opposition in der Wahrnehmungsperspektive, der erinnerte Schmerz auf inhaltlicher Ebene, die Angst und das Erstaunen bei der Reaktion des Sprechers wieder. Außerdem sind beide Gedichte durch die Kirchen-Motivik miteinander verbunden, die den Rahmen einer figurativen Welt absteckt, in der «espeutros» («Na catedral», v. 45), «fantasmas» (jeweils v. 72 und v. 51) und jene allgegenwärtigen «sombras» umherschwirren. Diesmal sind es nicht die Abbildungen der Heiligen, sondern die Glocken des Domes, die den Fluß der Rede vorantreiben:

Da Catedral campana

grave, triste e sonora, cand'ó raiar do día a toque d' alba tocas, no espazo silencioso soando malencónica, as túas bataladas non sei que despertares me recordan.

Foron algúns tan puros coma o fulgor da aurora, outros cal a esperanza qu'o namorado sońa, 
i á derradeira inquietos, mitá luz, mitá sombras, mitá un pracer sin nome, e mitá unha sorpresa aterradora.

(vv. 1-16)

In die unbestimmten glücklichen Erinnerungen, die die Glockenschläge auslösen, mischt sich bald eine Verunsicherung, in der sich erneut Gegensätze wie Licht und Dunkel, Überraschung, Schrecken und Wonnen vereinigen. Zudem geht das Geläut der Freude in Klänge der Trauer beim Sonnenaufgang über:

¿En donde van aqueles

despertares de dichas e de groria?

Pasaron para sempre:

mas ti, grave e sonora,

¡ai! ó romper do día,

ca túa voz malencónica

vés decote a lembrarnos

cada nacente aurora;

e parece qu'a morto

por eles e por min a un tempo dobras.

(vv. 31-40)

Am Ende spricht das lyrische Ich die Glocken an, um ihnen seinen bevorstehenden Tod kundzutun. Unmittelbar daran schließt der zweite Abschnitt an, in dem der Sprecher Meer, Himme — vielleicht auch Gott (vv. 53-56) - um Hilfe zur Errichtung des eigenen Grabes anfleht:

¡Mar! cas túas auguas sin fondo,

¡ceo! ca túa imensidá,

o fantasma que m'aterra

axudádeme a enterrar.

(vv. 49-52) 
Dieses Gespenst ist mit dem Sprecher eins, geht unbarmherzig vor ihm her, droht, ihn bis in die Ewigkeit zu begleiten, und überhäuft ihn gleichzeitig mit Spott (vv. 47-60). Im dritten Abschnitt schließlich wird das Gespenst identifiziert, für das das Grab bestimmt ist: «a memoria do pasado». Dem Gedächtnis gilt die Grabplatte, das schwarze Vergessen, und dem Nichts der Ruheplatz:

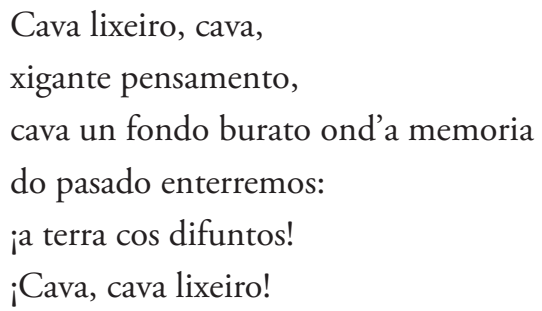

Der Rückgriff auf eine einfache Diktion, die direkte Ansprache abstrakter Gedanken und die Wiederholungen entsprechen der volkstümlichen Stillage vieler Gedichte Rosalías. Indes macht der Kontrast zum ernsten Gegenstand den ironischen Unterton dieser Verse unüberhörbar. Der Inhalt der Erinnerungen bleibt zwar unbestimmt, bildet jedoch das Thema des Gedichts, nämlich die veränderte Selbstwahrnehmung im Laufe der Zeit und der damit verbundene Bewußtseinskonflikt. Isoliert man den letzten Abschnitt dieser vierteiligen Komposition aus dem vorgeführten Zusammenhang (was wegen des kompositorischen Diskontinuitätsprinzips möglich ist), geht bei der Analyse des Gedichts "Cando penso que te fuches...» die durch dessen Kontext vorgegebene Perspektive verloren. R. Carballo erläutert den thematischen Zusammenhang der letzten drei Teile als einen Kampf um Selbstbefreiung von jenem fantasma oder sombra und erklärt die symbolische Tragweite des Zyklus folgendermaßen:

En la pieza II [“Cava lixeiro...»] se pretende hacer esto [sc. das Gespenst zu beerdigen]. En la III [«Cando tú...] se constata que la sombra permanecerá siempre, porque está dentro de uno. Identificados el fantasma y la sombra de los poemas I [«iMar!...»] y III, el II nos daría la clave del misterio. Ese fantasma que se quería enterrar, ese pasado para el que se pide una fosa y esa sombra que torna 
siempre, son una misma cosa, aludida simbólicamente en los poemas extremos, pero mencionada directamente en el medio. A memoria do pasado.

El fantasma del pasado. El recuerdo del pasado. La sombra del pasado. Del pasado en conjunto o de un pasado concreto.

Weit entscheidender als der abschließende Entzifferungsversuch ist für die hier angestrebte Textanalyse die Tatsache, daß sich in der poetischen Rede die Erinnerung als maßgebliche Subjektivierungsinstanz erweist, die das agonale Verhältnis des Einen zum Anderen im Akt des Sprechens integriert. Dieses zwiespältige Bewußtsein spiegelt sich dank der Verdoppelung des Selbst in das sprechende Ich und dessen Projektion als «negra sombra» wider. Diese Aufspaltung ist in "Cando penso que te fuches...” auch grammatikalisch vollzogen, und dabei forciert die poetische Rede den agonalen Modus der Subjektkonstituierung als Alteritätsbewußtsein. Erneut läßt sich ein dualistisches Modell in der Darstellung erkennen; bei der Figur der «negra sombra» geht es allerdings nicht um eine Verlustdialektik, wie bei der Figur des «ben perdido», sondern um eine Vervielfältigung des Selbst. Und wie im Falle des «ben perdido» waltet keine harmonisierende Lösung, so daß der Konflikt in der wahrgenommenen Differenz des Selbst bestehenbleibt:

En todo estás e ti es todo

pra min i en min mesma moras,

nin m’abandonarás nunca,

sombra que sempre m'asombras.

(vv. 69-84) 